\title{
Uncovering the Enablers, Benefits, Opportunities and Risks for Digital Open Government (DOG): \\ Enablers, Benefits, Opportunities and Risks for DOG
}

Muhammad Naeem, University of Worcester, Worcester, UK

\begin{abstract}
The systematic review approach has been used to collect, examine, interpret, and synthesize research regarding enablers, challenges, opportunities, risks, and the usefulness of open government. The current review adopted the meta-synthesis approach to conduct the systematic review on 61 selected research papers. The study has covered the enablers for such initiatives and how governments of various countries can achieve open government benefits like lower level of corruption, higher level of public awareness and education, high level of transparency, more democratic control, improve efficiency and effectiveness of public services, and improve public services. The author has extracted various risks and challenges that obstruct open government efforts from getting their full potential. The study is helpful for policymakers of those countries who are planning to implement an open government system in their countries. However, a cooperation bias is one of the most considerable limitations in research studies that are included in this systematic literature review.
\end{abstract}

\section{KEYWORDS}

Systematic Literature Review, Open Government, Enablers, Benefits, Opportunities, Risks starting on February 4, 2021 in the gold Open Access journal, International Journal of Public Administration in the Digital Age (converted to gold Open Access January 1, 2021), and will be distributed under the terms of the Creative Commons Attribution License (http://creativecommons.org/licenses/by/4.0/) which permits unrestricted use, distribution, and production in any medium, provided the author of the original work and original publication source are properly credited. 


\section{INTRODUCTION}

Transparency, accountability, collaboration, and citizen participations are the fundamental parameters of DOG (Arcelus, 2012; Saxena \& Muhammad, 2018; Lourenço et al., 2017). Therefore, DOG or open source data are received attraction and has become a very recent phenomenon. DOG is known as data sets that are derived from economics, tourism, transportation, geographical, industry, education and quality levels, public organizations performance and budgeting levels, energy science, traffic, health, food, climate, social work, weather, and technology (Davies, 2012; Saxena, 2018; Janssen et al., 2012). Janssen et al. (2012) have stated that significant total of public sector organizations has implemented DOG system but many organizations especially in developing and emerging countries are still unenthusiastic for DOG. Nam (2015) has indicated that adoption and implementation of DOG is not cheap and easy, but it is considered as resourceful innovation to establish systematic management for public services. According to researchers, limited literature is available that has been explored the enablers, barriers, opportunities, and benefits of DOG data especially in the context of Arab and developing countries (Saxena, 2017; Saxena, 2018). Previous studies have indicated that enablers, drivers, and barriers are usually varied organization to organization, culture to culture, and developed to developing countries (Barry \& Bannister, 2014; Grimmelikhuijsen et al., 2013; Hielkema \& Hongisto, 2013; Saxena, 2018; Susha et al., 2015). These studies have described the enablers, barriers, and drivers into four groups: managerial and organizational, environmental and institutional, regulatory and legal, and information technology. The process, procedures, policies, and laws of opening up data are recognized as incomplete and awkward for people, government, and other stakeholders (Evans \& Campos, 2013; Fuentes-Enriquez \& Rojas-Romero, 2013; Janssen et al., 2017). It is cumbersome because many government agencies are opened their data too simplistically, but designing an open database often requires change in processes, employee skills, culture, behavior, system, and organizational structure.

With the advent and rise of internet and information systems, government public services data is online available in order to reduce the level of corruption (Aslam et al., 2015; Aslam et al., 2016; Aslam et al., 2018). According to the European Commission Anti-Corruption Report in 2014, the European Union countries are facing 120-billion-euro loss (economic costs of corruption) per year. The core objective of this paper is to highlight the challenges, risks and benefits of DOG through the lens of existing studies conducted in different countries, public sector organizations, cultures, contexts, and regions. Most of the studies on DOG are conceptual based papers (Bertot et al., 2010; McDermott, 2010), informational technologies and system for capturing the benefits and power of open data (Charalabidis et al., 2011; Kalampokis et al., 2011), and elaborations of the empirical utilization of DOG data (Hausenblas, 2009; Napoli \& Karaganis, 2010). Furthermore, researchers argued that they were able to identify only one systematic literature and meta-analysis study in the context of DOG (Wirtz \& Birkmeyer, 2015). There are only very few studies available that are conducted on systematic literature review on DOG (Attard et al., 2015; Criado, 2018; De-Oliveira \& Silveira, 2018; Safarov et al., 2017; Wirtz \& Birkmeyer, 2015), and these are limited to DOG definition, intatives, uses, issues specifically to few western countries. None of the research study provides a brief analysis regarding the challenges, enablers, benefits, and opportunities that go beyond conceptual ideas, applications, global sketches, and individuals' projects. To date, authors of this study did not find single study that comprehensively discussed the challenges, enablers, opportunities, and benefits of DOG in the context of western and non-western countries.

There are three main objectives of this study. The first objective is to systematically gather, summarize, scrutinize, interpret, and synthesize the existing literature on challenges, benefits, and risks for DOG. The second objective is to comprehensively explain the values and accuracy regarding the qualitative and quantitative findings of the relevant studies. The third objective of this study is to offer rich description and grounded substantiation regarding how policy makers and stakeholders of various developing countries can use the enablers, opportunities, challenges, and benefits of DOG to 
successfully formulate and implement DOG system. The successful implementation of DOG system can enhance transparency, collaboration, citizens' participation, accountability, innovation, and economic development in a country (Luna-Reyes \& Ae-Chun, 2012; Lourenço, 2013; Von-Lucke \& Große, 2014). The current paper opted the method of systematic review of previous relevant studies to achieve the desire objectives (Attard et al., 2015; Criado, 2018; De-Oliveira \& Silveira, 2018; Safarov et al., 2017; Wirtz \& Birkmeyer, 2015). The current review considered different conceptual and theoretical studies regarding DOG and confined to sixty-one studies that are more relevant and serve the purpose. We believe the results of this study will support to formulate and implement DOG system by following the best practices of successful DOG system across the world.

\section{RESEARCH METHODOLOGY}

Kitchenham (2007) has explained that systematic literature review is known as repetitive process to find out all relevant literature related to specific research question or particular topic. The research study is based on what already has been done in the context of challenges, benefits, and risks for DOG. Systematic review method has been used because it is an appropriate method to gather the most relevant literature about relevant constructs (Tranfield et al., 2003). The major objective of systematic review is to gather, analyze, and interpret related studies by following predetermined review procedures, incorporating both the manual and automatic search strategies (Attard et al., 2015; De-Oliveira \& Silveira, 2018). These predefined review procedures and search strategies are helpful to capture related studies published in recent period. To deal with current systematic review, the authors have been used different digital resources for maximum data acquisition about the underlying concepts. These digital resources include Google Scholar, ISI Web of Knowledge, IEEE Xplore Digital Library, Emerald, Springer Link, Science direct and Wiley online library. There are multiple justifications behind selecting systematic review for current study (see table 1).

\section{Identification of Studies}

There are different types of search have been executed to get maximum articles about DOG. These searches used key variable, combination of key variable with outcomes, inner facets and their linkages with various successful and positive outcomes using digital resources such as Google Scholar, ISI Web of Knowledge, IEEE Xplore Digital Library, Emerald, Springer Link, Science direct and Wiley online library. For in-depth review, most cited as well as diverse articles are extracted from the references

Table 1. Rationale behind selecting systematic review

\begin{tabular}{|l|l|}
\hline $\begin{array}{l}\text { Rationale of Inclusion \& } \\
\text { Exclusion }\end{array}$ & $\begin{array}{l}\text { According to Tranfield et al. (2003), there is a clear criterion for inclusion and } \\
\text { exclusion of papers from the searched data based on logical ground. That element } \\
\text { gives a strong basis to current review and transparency as well. }\end{array}$ \\
\hline Coherence \& Precision & $\begin{array}{l}\text { According to Denyer and Neely (2004), systematic review contains a coherence } \\
\text { and precision of gathered data in a very clear way that induced reader to get benefit } \\
\text { from it as it is based on already defined logical system. }\end{array}$ \\
\hline Focus \& Equality & $\begin{array}{l}\text { According Chen et al. (2012), systematic review has more focused on mentioned } \\
\text { question and resultantly all search to elaborate it. Moreover, all the researched data } \\
\text { regarding particular topic has equal chances of selection. }\end{array}$ \\
\hline $\begin{array}{l}\text { Approachability \& Broad } \\
\text { Coverage }\end{array}$ & $\begin{array}{l}\text { According to Pittaway et al. (2004), systematic review has edge on other reviews } \\
\text { as it approaches to almost all relevant literature using different data based and } \\
\text { produced a refined version that is available to readers. }\end{array}$ \\
\hline Integration or synthesis & $\begin{array}{l}\text { Tranfield et al. (2003) highlighted the importance of synthesis using systematic } \\
\text { review as it the integration of all relevant studies and provide a unique solution to } \\
\text { the given problems in the light of already conducted studies. }\end{array}$ \\
\hline
\end{tabular}


list of key papers. Moreover, for current review, 381 papers on open data and DOG were included from 2000 to 2018 (two-decade data). Almost, the data about DOG and open data were extracted since inception of the discipline to 2018.

\section{Initial Selection Criteria}

At first, abstracts of the searched articles were keenly reviewed. The selection of systematic literature review papers has been done on the basis of key terms like DOG, benefits of DOG, benefits of open data, challenges for DOG, transparent public services, risks for DOG, enablers of DOG data, enablers of public government data, risks in consuming open data, and opportunities for public open data. Furthermore, only those related studies are included that clearly defined DOG and its inner facets with a promising effect on any outcome. The studying and analyzing of abstracts reduced the articles' up to 172. Only selected articles are reviewed in detail based on above-mentioned criteria. The main information that was extracted is article type, citations, key variables, method of analysis, response rate, context and validity of results (See figure 1).

\section{Final Selection Criteria}

After conducting the initial screening of selected articles, final screening is done based on relevance to the keywords of this study (i.e. enablers, opportunities, challenges, and benefits of open data or open government), response rate, validity of results, and citations of these selected articles. Only those articles are used in the review that is related to the key objectives of this study as well as has adequate response rate, validity and accuracy measures, published in reputed journals as well as good amount of citations, and generalized results. Moreover, Google scholar has been used to find out the well-known journals and citations of selected papers.

\section{SYSTEMATIC REVIEW RESULTS}

In total, sixty-one articles have been used for current review that meets stated criteria. These papers have conceptual, theoretical, practical, and contributions for society. These research papers uncovered the connection among DOG and corruption, public awareness and education, transparency, democratic control, efficiency and effectiveness of public services, innovation, new or improved services and products, participation, new knowledge, collaboration, community engagement, economic growth, economic development, accountability, trust, reputation, and improvement in public services. Following is the main presentation of review regarding DOG and various outcomes for the period of last two decades (from 2000 to 2018; Table 2 is showing the frequency of enabler, benefits, opportunities, and risks for DOG used in existing literature).

Figure 1. Research methodology

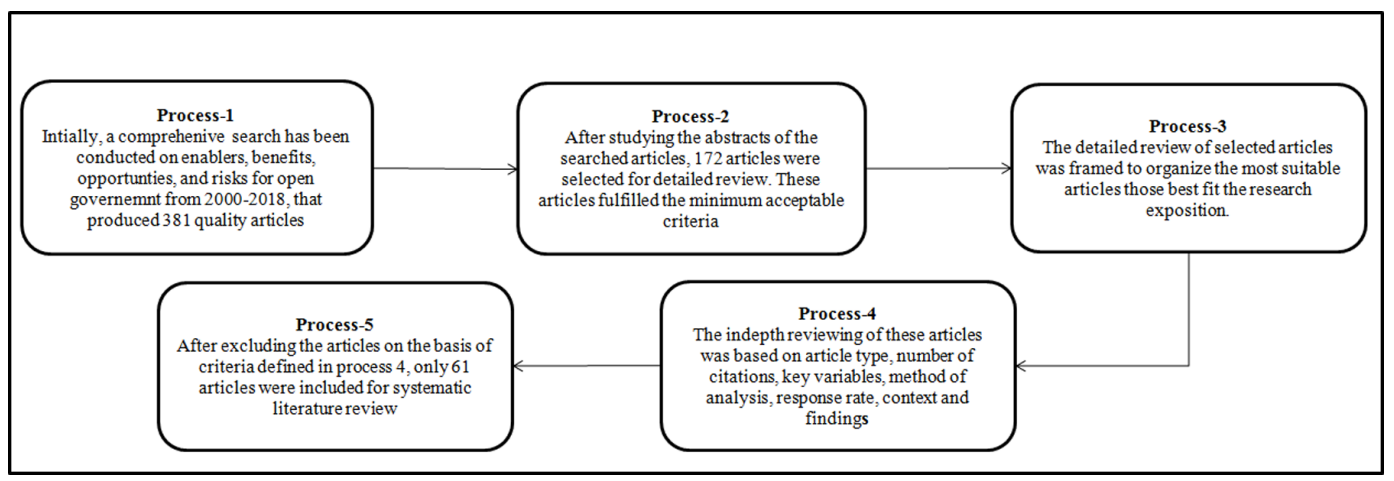




\section{Fundamentals of DOG}

\section{Definition of DOG}

In history, the idea of DOG has been discovered in political theory about hundreds years ago and traditional use of that term focus on open source, data, innovation, or standards in opening up a new method to the management of the top bureaucracy (Harrison et al., 2012, p. 922). Yu et al. (2012) have stated that the term "DOG" was purposefully used in USA in 1950s during the debate of political accountability and transparency in the perspective of freedom of information act. After this, the term of "DOG" has been critically discussed and expanded in the context of open source data and technological innovations. Yu et al. (2012) have stated that successful adoption of DOG means more economic opportunities, efficiency, effectiveness, and innovation in any country. The term 'DOG' remains abstract and unclear due to limited exploration of theories (Nam, 2015). According to Harrison et al. (2012, p. 922), even the term of DOG is remained in attraction and discussed from many years, but its accurate, acceptable, and generalizable meaning is still under construction. Similarly, Wirtz and Birkmeyer (2015) have stated that the term "DOG" has lack of integrative and basic definitions. Hood (2006, p. 25) has described the term 'open' as data available for transparency. On the other hand, openness may also know as an availability of online information and open interactions to interested citizens (Meijer et al., 2012). Generally, government agencies or institutions have three major driving factors to launch open data initiative such as efficiency, transparency, and innovation.

Table 2. Frequency of enablers, benefits, opportunities, and risks for DOG used in existing research

\begin{tabular}{|c|c|c|c|c|c|c|c|c|}
\hline \multirow[t]{2}{*}{ Name of Journal } & \multicolumn{8}{|c|}{ DOG data } \\
\hline & BOG & EOD & RPOD & OGOD & BODC & CPD & RCOD & COG \\
\hline Digital policy regulation and governance & 1 & 1 & 0 & 1 & 1 & 1 & 1 & 1 \\
\hline Future Internet & 1 & 0 & 0 & 1 & 1 & 1 & 0 & 1 \\
\hline Government Information Quarterly & 2 & 1 & 2 & 2 & 2 & 2 & 2 & 2 \\
\hline International journal of web engineering and technology & 1 & 2 & 1 & 1 & 1 & 1 & 1 & 1 \\
\hline Information systems management & 1 & 1 & 1 & 0 & 0 & 1 & 1 & 1 \\
\hline Information polity & 2 & 2 & 1 & 1 & 1 & 1 & 1 & 1 \\
\hline Information and management & 1 & 0 & 0 & 1 & 1 & 0 & 0 & 0 \\
\hline International conference on digital government research & 1 & 1 & 2 & 1 & 1 & 1 & 1 & 1 \\
\hline International conference on electronic government & 2 & 0 & 1 & 1 & 1 & 0 & 1 & 1 \\
\hline $\begin{array}{l}\text { International Conference on Theory and Practice of Electronic } \\
\text { Governance }\end{array}$ & 1 & 1 & 1 & & 1 & 1 & 0 & 0 \\
\hline IEE internet computing & 2 & 1 & 1 & 0 & 0 & 1 & 1 & 1 \\
\hline Journal of Knowledge economy & 2 & 2 & 2 & 1 & 1 & 1 & 2 & 2 \\
\hline Journal of information science & 1 & 1 & 1 & 1 & 0 & 0 & 0 & 1 \\
\hline Journal of policy analysis and management & 1 & 0 & 1 & 1 & 1 & 1 & 1 & 2 \\
\hline Journal of system integration & 2 & 0 & 0 & 1 & 0 & 0 & 0 & 1 \\
\hline Journal of economics and administrative sciences & 1 & 1 & 2 & 1 & 1 & 1 & 1 & 1 \\
\hline Public Administration Review & 2 & 2 & 5 & 4 & 2 & 1 & 3 & 1 \\
\hline Social science computer review & 2 & 0 & 0 & 1 & 1 & 0 & 1 & 2 \\
\hline Transforming, government, people, process, and technology (TGPPP) & 2 & 1 & 0 & 0 & 1 & 1 & 1 & 2 \\
\hline Total journals: 19 & 28 & 17 & 21 & 19 & 17 & 15 & 18 & 22 \\
\hline
\end{tabular}

Note: $B O G=$ Benefits of DOG, EOD= Enablers of Open Data, RPOD = Risks for Public open data, OGOD = Opportunities for Government open data, $\mathrm{BODC}=$ Benefits of Open data consumption, $\mathrm{RCPD}=$ Risks in Consuming public data, $\mathrm{RCOD}=$ Risks in consuming open data, $C O G=\mathrm{Challenges}$ for $\mathrm{DOG}$ 
Many researchers and practitioners are stated that open data is one of the main factors to enhance accountability and transparency (Bogdanović-Dinić et al., 2014; Grimmelikhuijsen et al., 2013; Hielkema and Hongisto, 2013; Saxena, 2018; Susha et al., 2015). Both transparency and accountability are the major facilitators of freedom of information act. DOG data can be known as data sets that are derived from political or socio-economic sector like economy, education, transportation, health, climate, and technology (Davies, 2012; Davies \& Frank, 2013).

The basic concept of DOG is focused to ensure that government agencies data accessible to every citizen of that country. Most of the previous offered definitions on DOG are focused on the access of online information for transparency purposes only but DOG is not limited to only transparency because it is increasingly focused on the importance of participation in decision making process from all the stakeholders of that system. Lathrop and Ruma (2010) have stated that DOG not merely means that citizens can gain access to given online information, but they may contribute through various significant ways. It is also found that there are various stakeholders like software developers, journalists, and citizens who are indirectly are directly interfere in execution and implementation of DOG data bases across the world. DOG means information and data from supply driven (responsive and reactive disclosure) to demand-driven transparency (proactive knowledge exchanging). Joan and Wouter (2015) have described DOG as a systematic management of public services data to enhance collaboration, participation, transparency among government agencies and general public. Here transparency is known as an ability to scrutinize government given information and decision-making process while participation can describe as an opportunity to contribute in decision-making processes. To date, the concept of DOG has become more complication and diverse, indicating significant ties to communication technologies and information (Nam, 2015; Lathrop \& Ruma, 2010). Another study has explained the concept of DOG as a governing and online knowledge sharing culture that enhance greater accountability, openness, responsive and efficient government services, and participation in services design and policymaking (Harrison et al., 2012).

\section{Enablers of DOG}

It is very important to find that which are the enablers and drivers of digital DOG. Furthermore, how these enablers and drivers are helpful to bring transparency, participation, and collaboration. Yang et al. (2015) have suggested the factors that are helpful in the adoption of DOG. For example, technological perspective (i.e. data format \& metadata, level of information, information system outsourcing), organizational perspective (i.e. perceived benefit, perceived loss, perceived effort, organizational culture, perceived liability, and authority involvement), the policy and legislation perspective (constraints on open data, policy \& legislation), the environmental perspective (peer effect, media and public). Joan and Wouter (2015) have presented and published report with the support of European commission regarding the enablers, drivers, and success factors of DOG. They have highlighted the three main enablers for DOG such as open data, authentic sources, shared solution or reusable, technical specifications, standards, and policies. Furthermore, researchers have also highlighted the drivers of DOG such as better public services and democratic values are helpful to promote participation and collaboration in public services as well as enhancing the transparency of government services. They have also highlighted other many drivers of DOG such as cost, efficiency, social benefits, jobs and economic growth, demand from civil society, and international mobility.

Researchers have highlighted the drivers of DOG such as accountability, compliance on the regulatory and legal layer, efficiency on the organizational layers, innovation on the environmental and institutional layer, enabling reuse of data or information, transparency, and opening up data by using IT layer (Saxena, 2018; Van-Veenstra \& Van-den-Broek, 2013). The process, procedures, policies, and laws of opening up data are recognized as incomplete and awkward for people, government, and other stakeholders. It is cumbersome because many government agencies are opened their data too simplistically but in reality, designing an open database often requires change in processes, employee skills, culture, people behavior, system, and organizational structure. Open data requires usually 
changes in multiple levels. The extent of literature on public sector in the context of change execution and implementation has highlighted that enablers and drivers to successfully implementation of change must be recognized at earlier stage. Moreover, there must be various plans before the change managers are opening transformation efforts for open data. DOG datasets must be freely accessible, available, retrievable, comprehensive, searchable, ensure datasets are completely uploaded and opened, comparable, allow connection with other datasets, allow interaction with data provider, and compatible (Hellberg \& Hedström, 2015; Zuiderwijk et al., 2012). Data sets should be browsed across various topics such as transport, health, government, economics, and business, education, society, cities, government spending, government income, government mapping, town, justice, and crime, format (i.e. XL, CSV, JPEG, XLSX, XLS) tags (i.e. banking, universities, air, bureau of internal revenue, and department of health). Previous studies have indicated that enablers, drivers, and barriers are usually varied organization to organization, culture to culture, and country to country (Grimmelikhuijsen et al., 2013; Hielkema \& Hongisto, 2013; Saxena, 2018; Susha et al., 2015). These studies have described the enablers, barriers, and drivers into four groups: managerial and organizational, environmental and institutional, regulatory and legal, and information technology. There are different enablers are found in previous literature that can foster the DOG data like technology layers, usefulness of database, value for others (i.e. societal and economic value) and political leadership, easier accessibility to data on the IT layer, management on the managerial and organizational layer, and data stewardship.

\section{Digitalization of DOG}

Different developed countries like USA, Australia, UK, and Canada are increasingly focused to enhance their investment budget with the purpose to deliver DOG data in simple, cheaper, faster ways. Figure 2 given below is showing the important points for completion of digital roadmap objectives.

For ensuring the success of digitalization, designing a digital transformation map and constructing a public services dashboard are one of the main components (Bertot et al., 2014). There are some principles that must be followed to ensure the success of digitalization of DOG such as data must be free and online, timely and easily accessible for each stakeholder, analyzable using various graphs and charts, available without any legal (i.e. license) and discrimination barriers, ensure data publishing with trust and permanence, ensure the openness for stakeholders (i.e. input, review, coordination, etc.), maintain high level of accuracy and lower level of cost during digitalization of DOG (Bertot et al., 2014).

Figure 2. Important points for completion of digital roadmap objectives Adopted from (Lathrop and Ruma, 2010)

1 Deliver a whole-of-government digital transformation roadmap.

2 Release agency-level digital transformation roadmaps.

3 Release and promote a beta version of the Digital Marketplace for ICT procurement.

(4) Release and promote a live dashboard measuring the performance of government services, with user satisfaction being one of the key performance indicators. 


\section{Benefits of DOG}

DOG has explained the benefits that are creating attraction for many countries such as selfempowerment and involvement to the citizens, accountability of agencies and public, economic development and growth, and continuous learning and innovation by re-using of online data. Open data is strongly based on the usage of information and communication technology to create innovation and diffusion. Currently, in open data approaches, researchers are struggling to overcome the barriers regarding how efficiently and effectively open data can be captured, stored, reused, processed, and output (Barry \& Bannister, 2014 Grimmelikhuijsen et al., 2013; Hielkema \& Hongisto, 2013; Saxena, 2018; Susha et al., 2015). Finally, DOG believes that the given data or information should be transparent to take optimal decision and stakeholders of data should be acted to make it more fair and transparent. Only the concern is to be exploiting new ways to empower general public individually and organizational collectively in the processes of DOG (Lathrop \& Ruma, 2010).

Previous studies have been undertaken to observe how a high level of transparency can bring several key benefits such as increase the level of civic participation, government efficiency, and accountability in any developed or developing country (Chun, 2010; Grimmelikhuijsen, 2013). Furthermore, it is also found that high level of transparency in DOG data can enhance the level of public trust and decrease the level of corruption (Grimmelikhuijsen, 2013). A study has been indicated that how high level of transparency can bring major economic growth because "public reuse of government data is anticipated to provide economic and social value to spur growth, promote a knowledge economy, and help the public help itself" (Linders, 2011). Existing literature in this field has highlighted that future studies must move towards explaining about how government can collect and distributed aggregate information and data that are accessible to the interested public at low level of cost, and the extent to which this open source data is being used (Da-Silva \& Dobránszki, 2015; Hollyer, 2012; Grimmelikhuijsen, 2013; Hielkema \& Hongisto, 2013; Saxena, 2018; Susha et al., 2015). Literature on DOG has explained the benefits that are creating attraction for many countries such as self-empowerment and involvement to the citizens, accountability of agencies and public, economic development and growth, and continuous learning and innovation by re-using of online data (Lundqvist, 2012; Janssen et al., 2012; Huijboom \& Van-den-Broek, 2011; Zuiderwijk et al., 2012). The study is focused in the implementation and adoption of DOG due to various benefits: information is accessible at anytime and anywhere, greater level of efficiency and effectiveness, enhance the speed of communication, and increase the level of citizen participation (Lundqvist, 2012; Janssen et al., 2012; Huijboom \& Van-den-Broek, 2011; Zuiderwijk et al., 2012).

\section{Opportunities for DOG}

DOG or open source data are received attraction and has become a very recent phenomenon. The "United Nations Millennium Development Goals established in 2000" focused to enhance accessibility of public services information in order to deliver human and civil rights (Linders, 2011). The USA, UK, and Canada are the pioneered countries to transform offline data to online for the interested citizens. According to Huijboom and Van-den-Broek (2011), some advanced countries such as UK, Australia, Denmark, USA, and Spain have successful developed the laws and policies for DOG data. On the other hand, Kenya and Indonesia have no efforts or lower level of efforts and knowledge to determine the laws and policies on open data (Schwegmann, 2012). Saxena (2017) has argued that Arab and developing countries are far behind in formulating and implementing open data laws compared to developed countries. DOG enhances citizens participation in discussion, searching online data and records, learning and awareness about key public services offered by DOG agencies. DOG has set out to perform many functions such as opening and exchanging data to enhance participation in policy design and delivery, reuse of online given assets, transparency of government, and collaboration on successful delivery of public services (Lathrop \& Ruma, 2010). DOG is a system that aims to provide open, shared, and interned based serviced that are characterized by purposeful, declared, deliberate 
effort to enhance collaborate and openness in the delivery of services (Bizer et al., 2009; Bertot et al., 2012). Digital government services are key determinants in the successful implementation of DOG.

Researchers have evaluated the DOG in the context of bureaucratic, political, technological, and economic perspectives. Bureaucratic perspective is more closely related to the government services, policies, regulations, procedures, and strategies to support public services delivery though public sector organizations. While technological perspective is helpful to improve data delivery infrastructure and reusability of data or information. Generally, government agencies or institutions have three major driving factors to launch open data initiative such as efficiency, transparency, and innovation. Many researchers and practitioners are stated that open data is one of the main factors to enhance accountability and transparency (Grimmelikhuijsen et al., 2013; Hielkema \& Hongisto, 2013; Saxena, 2018; Susha et al., 2015). Both transparency and accountability are the major facilitators of freedom of information act. It has found that NGO and general public of UK and USA forced their government agencies to online their data so that they can evaluate the accountability and transparency of government data. Open data is considered as a factor to foster economic growth and innovation in organizations. For example, the experts of DOG data have reported in European commission report regarding the economic value (i.e. 70-140 billion euros) in European countries only. Various information technologies such as social media and semantic web have become core factor to enhance capability to design, produce, exchange, reuse, and innovate DOG data (Bertot, et al., 2012; EggerPeitler \& Polzer, 2014). These informational technologies and online platform have given rise to open innovation, open standards, open source, openness in organizational strategy, open web platforms, openness in public sector agencies, open data, and DOG. Now-a-days, there are plenty of government agencies that are involved in publishing PSI like legal documents, geospatial data, educational data, crime statistics, traffic data, and weather forecasts.

\section{Challenges of DOG}

Zuiderwijk and Janssen (2014a) have highlighted the major risks of open data like misinterpretation of data, misuse of data, and violating privacy. They also stated that low quality can negatively influence the comparison, analysis, decision, and conclusion of stakeholders. Previous studies have highlighted number of risks that can negatively impact the quality and success of DOG data such as sharing data openly as an afterthought, privacy may be violated inadvertently, negative consequences for public government, published government data may have lower quality and biasness, misuse and misinterpretation of published government data, important decision are made based on poor quality of published or shared information, unclear responsibility and accountability, lower level of intention for resolving societal problems, limited information about data publication policy and lower level of attention for public value (Colborne \& Smit, 2017; Martin et al., 2013; Yang \& Shiang, 2015; Lee et al., 2002; Zuiderwijk \& Janssen, 2014b).Gonzalez-Zapata and Heeks (2015) have described the multiple perspectives of the term DOG, open data, or government data. For example, data government means government is largest holder, user, collector, or producer of services data and information related to citizens, businesses, and organizations. However, a particular concern in government data is about the limitation in the use of data within public sector organizations or agencies (Conradie \& Choenni, 2012; Conradie \& Choenni, 2014). Open data methods are not limited to any sector or specific boundaries. There are some risks that can create hurdles in transformation towards successful adoption of DOG such as lack of champions, experts, or leadership, low level of guidance, lack of experiences, lower level of reusability, immature online knowledge exchanging culture, confusion with cooperation and coordination, and bureaucratic inertia (Colborne \& Smit, 2017; Harrison et al., 2012; Joan \& Wouter, 2015; McDermott, 2010; Lathrop \& Ruma, 2010).

There are several risks that have indicated as a threat to DOG, for example, legacy systems, lack of standardization, limited quality, fragmented databases, and IT layer has poor data structures (Dawes, \& Helbig, 2010; Saxena, 2018; Van-Veenstra \& Van-den-Broek, 2013). Complete of the changes is one of the most important risks in the context of managerial and organizational layer. 
Lower level of support of user (in terms of their feedback), privacy, classified information as barrier, data protection, closed or bureaucratic culture of government organizations, privacy, environment and institutional layer are major barriers in the perspective of regulatory and legal layer. Previous studies have stated various barriers for DOG like privacy risks, lack of interest, security risks, low data quality, low level of reputation of government organization, unclear business case for open data, embedding open data in government institutions strategies (Harrison et al., 2012; Joan \& Wouter, 2015; Saxena, 2018; Van-Veenstra \& Van-den-Broek, 2013).

According to recent studies, most government agencies could not recognize the significance, value, and benefit of open data (Yang et al. 2015; Saxena, 2017) (Table 3). Many national and local government agencies have completed their work to specify policies that are helpful to use latest technologies to use DOG data (Martin, 2014). For example, recently South Korea has specified some "open data laws" and ensure that open data available freely to organizations, communities, and citizens (Jung and Park, 2015). In 2012-13, the UK has formulated and implemented laws and policies on DOG (Bates, 2014). Many countries have done intensive efforts to ensure transparency in data sets available for public services but, yet it has become difficult to examine the transparency of data and effective utilization of given data sets. Furthermore, Even US transparency procedures and policies are focused to enhance relationship between economic growth and transparency but there are no direct measures of transparency have been found yet (Orszag, 2009; Linders, 2011; Burwell, 2013). Yang et al. (2015) have highlighted that there are no appropriate methods, facts, and figures are available about whether open data initiatives are successful in developed and developing countries. Figure 3 shows the DOG adaption model.

\section{CONCLUSION}

The study has successfully concluded the enablers, benefits, opportunities, and risks for DOG. By using systematic literature review approach, the study has collected the main enablers for DOG such as open data, authentic sources, shared solution or reusable, technical specifications, standards, and policies cost, efficiency, social benefits, jobs and economic growth, demand from civil society,

Table 3. Enablers, benefits, challenges, and opportunities of DOG

\begin{tabular}{|c|c|}
\hline Enablers of DOG & Benefits of DOG \\
\hline $\begin{array}{l}\text { Open data } \\
\text { Authentic sources } \\
\text { Shared solution/reusable } \\
\text { Technical specifications, standards \& policies } \\
\text { Cost of DOG system } \\
\text { Efficiency and effectiveness } \\
\text { Social benefits and economic growth } \\
\text { Accountability and transparency }\end{array}$ & $\begin{array}{l}\text { Self-empowerment } \\
\text { Citizens participation } \\
\text { Accountability of agencies and public } \\
\text { Continuous learning and innovation } \\
\text { Optimal decision making } \\
\text { Lower level of corruption } \\
\text { High level of public trust } \\
\text { Increase the communication speed } \\
\text { Enhance the information accessibility }\end{array}$ \\
\hline Challenges of DOG & Opportunities for DOG \\
\hline $\begin{array}{l}\text { Misinterpretation of data } \\
\text { Misuse of data } \\
\text { Violating privacy } \\
\text { Low quality of data shared } \\
\text { Biasness from information provider } \\
\text { Unclear responsibility and accountability } \\
\text { Lower level of intention for resolving societal problems } \\
\text { Limited information about data publication policy } \\
\text { Lower level of reusability }\end{array}$ & $\begin{array}{l}\text { Increase public access for open data } \\
\text { Enhance public learning and awareness } \\
\text { Increase involvement in policy design and delivery } \\
\text { Reuse of data in table, chart, and figure } \\
\text { Transparency and responsible government } \\
\text { High level of public services and collaboration } \\
\text { Improves data delivery infrastructure } \\
\text { Enhance economic value }\end{array}$ \\
\hline
\end{tabular}


Figure 3. DOG adoption model

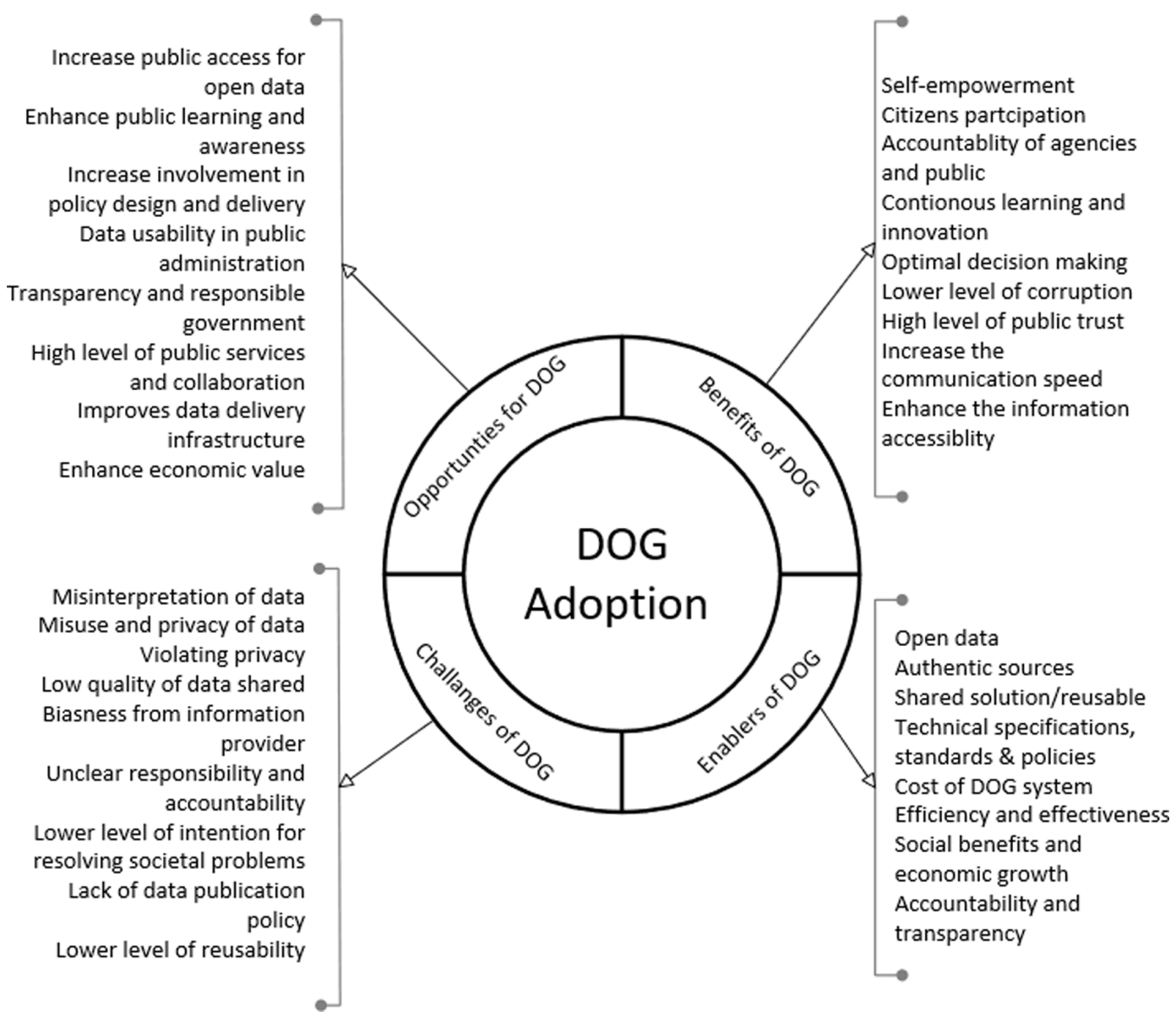

and international mobility. There are many benefits for formulation and implementation of DOG such as increase the level of civic participation, speed of communication, innovation and diffusion, government efficiency, self-empowerment and involvement to the citizens, accountability of agencies and public, economic development and growth, continuous learning and innovation by re-using of online data. There are number of opportunities like DOG enhances citizens participation in discussion, searching online data and records, learning and awareness, new ideas, knowledge exchanging, innovation, product improvement and development, transparency of government, and collaboration on successful delivery of public services. There are some risks that can create hurdles in transformation towards successful adoption of DOG such as lack of champions, experts, or leadership, low level of guidance, lack of experiences, lower level of reusability, immature online knowledge exchanging culture, confusion with cooperation and coordination, and bureaucratic inertia. It is also found that by using open data approaches, stakeholders are struggling to overcome the barriers regarding how efficiently and effectively open data can be captured, stored, reused, processed, and output. The study has selected research papers from both developed and developing countries. By using the findings of this study, developing countries can adopt successful practices for DOG and minimize the risks that can create hurdles in successful implementation of DOG system. The study has offered a cost and benefit analysis of DOG with the purpose to enhance level of awareness and motivation among the stakeholders of DOG (Table 4). This type of study can enhance motivation among stakeholders 
regarding how beneficial is to formulate and implement DOG system in any country. Findings of this study will enhance the level of awareness of policy markers about the challenges and opportunities of DOG so that they can design error free and effective DOG system. Cooperation bias is usually occurred because previous studies on DOG and open data have highlighted that respondents of their studies are more interested to over-estimate their level of participation and published data quality to enhance the success of DOG system.

\section{Research Gaps}

The final section of systematic literature review highlighted research gaps especially related to issues and enablers, conceptual framework, and methodology approach of reviewed papers related to DOG. We are hopeful that these research gaps will provide clearly guideline to researchers regarding what is/are important to explore/investigate in future studies.

\section{Gaps in Issues}

Janssen et al. (2012) have stated that significant total of public sector organizations has implemented DOG system but many organizations especially in developing and emerging countries are still unenthusiastic for DOG. Most of these studies have stated the issues of required infrastructure and regulations, as well as organizational and financial constraints. However, limited research literature is present to address the micro level issues such lower level of trust, lack of responsibility, lack of data quality, lower level of awareness, lack of education, no clear digitization process, lack of resources and lower level of participation from each stakeholder are the major issues. Furthermore, it is also found that level of technology usage, work complexity, openness to change, level of education, level of awareness, level of usefulness are very low especially in developing and Arab countries. But there is scant literature that address how government can design clear roadmap to overcome these micro level barriers especially in the context of Arab and developing countries (Saxena, 2017; Saxena, 2018). It is cumbersome because many government agencies are opened their data too simplistically, but designing an open database often requires change in processes, employee skills, culture, behavior, system, and organizational structure (Bertot et al., 2014). Nam (2015) has indicated that adoption and implementation of open government is not cheap and easy, but it is considered as resourceful innovation to establish systematic management for public services. According to researchers, limited

Table 4. Cost and benefit analysis of DOG based on systematic literature review

\begin{tabular}{|c|c|c|}
\hline & Implement & Impact \\
\hline Cost & $\begin{array}{l}\text { Several studies have suggested that it very expensive } \\
\text { method to digitalize all the traditional-based data of } \\
\text { public sector organizations (Joan and Wouter, 2015; } \\
\text { Nam, 2015). }\end{array}$ & $\begin{array}{l}\text { According to the European Commission Anti- } \\
\text { Corruption Report in 2014, the European Union } \\
\text { countries are facing 120-billion-euro loss (economic } \\
\text { costs of corruption) per year. By implementing } \\
\text { effective DOG, the amount of losses/corruption can } \\
\text { be minimized. }\end{array}$ \\
\hline Services & $\begin{array}{l}\text { Nam }(2015) \text { has indicated that adoption and } \\
\text { implementation of open government is considered } \\
\text { as resourceful innovation to establish systematic } \\
\text { management for public services. }\end{array}$ & $\begin{array}{l}\text { DOG is helpful to achieve new or improved services } \\
\text { and products, participation, new knowledge, } \\
\text { economic growth, economic development, } \\
\text { accountability, trust, reputation, and improvement in } \\
\text { public services. }\end{array}$ \\
\hline Society & $\begin{array}{l}\text { DOG is offering public services which can bring } \\
\text { benefits like lower level of corruption, higher level } \\
\text { of public awareness and education, collaboration, } \\
\text { community engagement, high level of transparency, } \\
\text { more democratic control, efficiency and } \\
\text { effectiveness of public services, innovation. }\end{array}$ & $\begin{array}{l}\text { DOG enhances citizens participation in discussion, } \\
\text { searching online data and records, learning and } \\
\text { awareness, new ideas, and knowledge exchanging } \\
\text { among individuals of societies. }\end{array}$ \\
\hline
\end{tabular}


literature is available that has been explored the enablers, barriers, opportunities, and benefits of DOG data especially in the context of Arab and developing countries (Saxena, 2017; Saxena, 2018). Previous studies have indicated that enablers, drivers, and barriers are usually varied organization to organization, culture to culture, and developed to developing countries (Barry, \& Bannister, 2014; Grimmelikhuijsen et al., 2013; Hielkema \& Hongisto, 2013; Saxena, 2018; Susha et al., 2015). In the light of reviewed literature, future researchers can investigate what are challenges and risks in opening digitalization process especially in the perspective of developing, Arab, or MENA countries.

\section{Gaps in Conceptual Approach}

The term 'DOG' remains abstract and unclear due to limited exploration of theories (Nam 2015). According to Harrison et al. (2012, p. 922), even the term of DOG is remained in attraction and discussed from many years, but its accurate, acceptable, and generalizable meaning is still under construction. Most of studies have conducted to offer conceptual framework based on secondary data on issues, strategies, power and benefits, formulation, and application of DOG data (Charalabidis et al., 2011; Kalampokis et al., 2011). Furthermore, different studies have described different enablers of DOG in offered conceptual frameworks (Charalabidis et al., 2011; Kalampokis et al., 2011). During systematic literature review, we are also found that influencing factor (individual, organizational, cultural, political, legal, financial) on DOG are vary among conducted studies. Furthermore, we did not find a single study which offers an estimate about cost and benefit analysis of DOG using any graph, chart, or framework. It is also evidence from reviewed literature that academic researchers did not provide clear picture regarding the social and innovation after successful implementation of DOG. There is an opportunity for future researchers to address imbalance evidences which may add uniqueness in existing literature. Data collection from poor countries and different contexts may offer deep understanding regarding the true estimation of cost and benefit analysis and social impact in opening DOG.

\section{Gaps in Methodology Approach}

There are very few studies available that are conducted on systematic literature review on DOG (Attard et al., 2015; Criado, 2018; De-Oliveira \& Silveira, 2018; Safarov et al., 2017; Wirtz \& Birkmeyer, 2015), but these are limited to DOG definitions, initiatives, uses, issues specifically to few western countries. Therefore, findings are only limited to some geographical or locational based areas. Furthermore, most of the available data on DOG has been gathered based on literature review and using qualitative methods. However, qualitative data is not representative of wider populations or non-users as well as unable to provide validity of results. Therefore, future researcher can use mixed method approach or quantitative design to confirm the reliability and validity of conceptual frameworks and other influential factors. 


\section{REFERENCES}

Arcelus, J. (2012). Framework for useful transparency websites for citizens. In Proceedings of the 6th International Conference on Theory and Practice of Electronic Governance (pp. 83-86). New York: ACM. doi:10.1145/2463728.2463749

Aslam, U., Arfeen, M., Mohti, W., \& Rahman, U. U. (2015). Organizational cynicism and its impact on privatization (evidence from federal government agency of Pakistan). Transforming Government: People. Process and Policy, 9(4), 401-425. doi:10.1108/TG-11-2014-0054

Aslam, U., Ilyas, M., Imran, M. K., \& Rahman, U. U. (2016). Detrimental effects of cynicism on organizational change: An interactive model of organizational cynicism (a study of employees in public sector organizations). Journal of Organizational Change Management, 29(4), 580-598. doi:10.1108/JOCM-12-2014-0231

Aslam, U., Muqadas, F., Imran, M. K., \& Saboor, A. (2018). Emerging organizational parameters and their roles in implementation of organizational change. Journal of Organizational Change Management, 31(5), 1084-1104. doi:10.1108/JOCM-08-2017-0300

Attard, J., Orlandi, F., Scerri, S., \& Auer, S. (2015). A systematic review of DOG data initiatives. Government Information Quarterly, 32(4), 399-418. doi:10.1016/j.giq.2015.07.006

Barry, E., \& Bannister, F. (2014). Barriers to open data release: A view from the top. Information Polity, 19(1, 2), 129-152.

Bates, J. (2014). The strategic importance of information policy for the contemporary neoliberal state: The case of DOG Data in the United Kingdom. Government Information Quarterly, 31(3), 388-395. doi:10.1016/j. giq.2014.02.009

Bertot, J. C., Butler, B. S., \& Travis, D. (2014). Local big data: The role of libraries in building community data infrastructures. In Proceedings of the 15th Annual International Conference on Digital Government Research, Aguascalientes, Mexico, June 18-21 (pp. 17-23). doi:10.1145/2612733.2612762

Bertot, J. C., Jaeger, P. T., \& Grimes, J. M. (2010). Using ICTs to create a culture of transparency: E-government and social media as openness and anti-corruption tools for societies. Government Information Quarterly, 27(3), 264-271. doi:10.1016/j.giq.2010.03.001

Bertot, J. C., Jaeger, P. T., \& Hansen, D. (2012). The impact of polices on government social media usage: Issues, challenges, and recommendations. Government Information Quarterly, 29(1), 30-40. doi:10.1016/j. giq.2011.04.004

Bizer, C., Heath, T., \& Berners-Lee, T. (2009). Linked data-the story so far. International Journal on Semantic Web and Information Systems, 5(3), 1-22. doi:10.4018/jswis.2009081901

Bogdanović-Dinić, S., Veljković, N., \& Stoimenov, L. (2014). How open are public government data? An assessment of seven open data portals. In Measuring E-government efficiency (pp. 25-44). New York, NY: Springer.

Borzacchiello, M. T., \& Craglia, M. (2012). The impact on innovation of open access to spatial environmental information: A research strategy. International Journal of Technology Management, 60(1-2), 114-129. doi:10.1504/IJTM.2012.049109

Charalabidis, Y., Ntanos, E., \& Lampathaki, F. (2011). An architectural framework for DOGal data for researchers and citizens. Paper presented at the Electronic government and electronic participation joint proceedings of ongoing research and projects of IFIP EGOV and ePart 2011.

Colborne, A., \& Smit, M. (2017, December). Identifying and mitigating risks to the quality of open data in the post-truth era. In Proceedings of the 2017 IEEE International Conference on Big Data (Big Data) (pp. 25882594). IEEE. doi:10.1109/BigData.2017.8258218

Conradie, P., \& Choenni, S. (2012, October). Exploring process barriers to release public sector information in local government. In Proceedings of the 6th international conference on theory and practice of electronic governance (pp. 5-13). ACM. doi:10.1145/2463728.2463731 
Conradie, P., \& Choenni, S. (2014). On the barriers for local government releasing open data. Government Information Quarterly, 31, S10-S17. doi:10.1016/j.giq.2014.01.003

Cranefield, J., Robertson, O., \& Oliver, G. (2014). Value in the mash: Exploring the benefits, barriers and enablers of open data apps.

Criado, J. I. (2018). Revisiting the Open Government Phenomenon. A Meta-Analysis of the International Literature. JeDEM eJournal of eDemocracy and Open Government, 10(1), 50-81.

Da Silva, J. A. T., \& Dobránszki, J. (2015). Potential dangers with open access data files in the expanding open data movement. Publishing Research Quarterly, 31(4), 298-305. doi:10.1007/s12109-015-9420-9

Davies, T., \& Frank, M. (2013). there's no such thing as raw data': Exploring the sociotechnical life of a government dataset. In Proceedings of the 5th Annual ACM Web Science Conference (pp. 75-78). New York: ACM.

Davies, T. G., \& Bawa, Z. A. (2012). The promises and perils of DOG data (OGD). The Journal of Community Informatics, 8(2). Retrieved from http://cijournal.org/index.php/ciej/article/view/929

Dawes, S. S., \& Helbig, N. (2010, August). Information strategies for DOG: Challenges and prospects for deriving public value from government transparency. In Proceedings of the 2017 International Conference on Electronic Government (pp. 50-60). Springer. doi:10.1007/978-3-642-14799-9_5

De-Oliveira, E. F., \& Silveira, M. S. (2018, May). DOG data in Brazil a systematic review of its uses and issues. In Proceedings of the 19th Annual International Conference on Digital Government Research: Governance in the Data Age (p. 60). ACM.

Deogirikar, A. (2014). The Impact of DOG on Innovation: Does Government Transparency Drive Innovation? [Doctoral dissertation]. Georgetown University.

Egger-Peitler, I., \& Polzer, T. (2014). Open data: European ambitions and local efforts. experiences from austria. In DOG (pp. 137-154). New York, NY: Springer. doi:10.1007/978-1-4614-9563-5_9

Elbadawi, I. A. (2012). The state of DOG data in GCC countries. Retrieved from https://books.google.de/boo $\mathrm{ks} ? \mathrm{hl}=\mathrm{en} \& \mathrm{lr}=\& \mathrm{id}=\mathrm{qKQHBAAAQBAJ} \& \mathrm{oi}=\mathrm{fnd} \& \mathrm{pg}=\mathrm{PA} 193 \& \mathrm{dq}=\mathrm{gcc}+$ countries+ open + data\&ots $=7 \mathrm{JxwHb}$ YIA\&sig=b6HJrhdK_JpKn8pUTB4DBdgFsLI\#v=onepage \&q=gcc\%20countries\%20open\%20data\&f=false

Evans, A. M., \& Campos, A. (2013). DOG initiatives: Challenges of citizen participation. Journal of Policy Analysis and Management, 32(1), 172-185. doi:10.1002/pam.21651

Fuentes-Enriquez, R., \& Rojas-Romero, Y. (2013). Developing accountability, transparency and government efficiency through mobile apps: The case of Mexico. In Proceedings of the 7th International Conference on Theory and Practice of Electronic Governance (pp. 313-316). New York: ACM. doi:10.1145/2591888.2591944

Grimmelikhuijsen, S., Porumbescu, G., Hong, B., \& Im, T. (2013). The effect of transparency on trust in government: A cross-national comparative experiment. Public Administration Review, 73(4), 575-586. doi:10.1111/puar.12047

Harrison, T. M., Guerrero, S., Burke, G. B., Cook, M., Cresswell, A., Helbig, N., \& Pardo, T. et al. (2012). DOG and e-government: Democratic challenges from a public value perspective. Information Polity, 17(2), 83-97. doi:10.3233/IP-2012-0269

Harrison, T. M., Pardo, T. A., \& Cook, M. (2012). Creating DOG ecosystems: A research and development agenda. Future Internet, 4(4), 900-928. doi:10.3390/fi4040900

Hausenblas, M. (2009). Exploiting Linked Data to Build Web Applications. IEEE Internet Computing, 13(4), $68-73$.

Hellberg, A. S., \& Hedström, K. (2015). The story of the sixth myth of open data and DOG. Transforming Government: People, Process and Policy, 9(1), 35-51.

Hielkema, H., \& Hongisto, P. (2013). Developing the Helsinki smart city: The role of competitions for open data applications. Journal of the Knowledge Economy, 4(2), 190-204. doi:10.1007/s13132-012-0087-6 
Janssen, M., Charalabidis, Y., \& Zuiderwijk, A. (2012). Benefits, adoption barriers and myths of open data and DOG. Information Systems Management, 29(4), 258-268. doi:10.1080/10580530.2012.716740

Janssen, M., Matheus, R., Longo, J., \& Weerakkody, V. (2017). Transparency-by-design as a foundation for DOG. Transforming Government: People. Process and Policy, 11(1), 2-8.

Joan, B., \& Wouter, D. (2015). Towards faster implementation and uptake of DOG. European Commission, Directorate-General of Communications Networks Content \& Technology. doi:10.2759/143988

Kalampokis, E., Tambouris, E., \& Tarabanis, K. (2011). A classification scheme for open government data: Towards linking decentralised data. International Journal of Web Engineering and Technology, 6(3), $266-285$. doi:10.1504/IJWET.2011.040725

Kucera, J., \& Chlapek, D. (2014). Benefits and risks of DOG data. Journal of Systems Integration, 5(1), 30-41. doi:10.20470/jsi.v5i1.185

Lathrop, D., \& Ruma, L. (2010). DOG: Collaboration, transparency, and participation in practice. O'Reilly Media, Inc.

Lee, Y. W., Strong, D. M., Kahn, B. K., \& Wang, R. Y. (2002). AIMQ: A methodology for information quality assessment. Information \& Management, 40(2), 133-146. doi:10.1016/S0378-7206(02)00043-5

Linders, D., \& Wilson, S. C. (2011, June). What is DOG?: one year after the directive. In Proceedings of the 12th Annual International Digital Government Research Conference: Digital Government Innovation in Challenging Times (pp. 262-271). ACM.

Lourenço, R. P. (2013, September). DOG portals assessment: a transparency for accountability perspective. In Proceedings of the International Conference on Electronic Government (pp. 62-74). Springer, Berlin, Heidelberg. doi:10.1007/978-3-642-40358-3_6

Lourenço, R. P., Piotrowski, S., \& Ingrams, A. (2017). Open data driven public accountability. Transforming Government: People. Process and Policy, 11(1), 42-57.

Luna-Reyes, L. F., \& Ae Chun, S. (2012). DOG and public participation: Issues and challenges in creating public value. Information Polity, 17(2), 77-81. doi:10.3233/IP-2012-0274

Martin, C. (2014). Barriers to the DOG data agenda: Taking a multi-level perspective. Policy and Internet, 6(3), 217-240. doi:10.1002/1944-2866.POI367

Martin, S., Foulonneau, M., Turki, S., \& Ihadjadene, M. (2013). Risk analysis to overcome barriers to open data. Electronic. Journal of E-Government, 11(1), 348.

Martin, S., Foulonneau, M., Turki, S., \& Ihadjadene, M. (2013, June). Open data: Barriers, risks and opportunities. In Proceedings of the 13th European Conference on eGovernment (ECEG 2013), Academic Conferences and Publishing International Limited, Reading (pp. 301-309).

McDermott, P. (2010). Building DOG. Government Information Quarterly, 27(4), 401-413. doi:10.1016/j. giq.2010.07.002

Meijer, A. J., Curtin, D., \& Hillebrandt, M. (2012). DOG: Connecting vision and voice. International Review of Administrative Sciences, 78(1), 10-29. doi:10.1177/0020852311429533

Nam, T. (2015). Challenges and concerns of DOG: A case of government 3.0 in Korea. Social Science Computer Review, 33(5), 556-570. doi:10.1177/0894439314560848

Napoli, P. M., \& Karaganis, J. (2010). On making public policy with publicly available data: The case of U.S. communications policymaking. Government Information Quarterly, 27(4), 384-391. doi:10.1016/j. giq.2010.06.005

Obama, B. (2009). Transparency and DOG, memorandum for the heads of executive departments and agencies. Retrieved from http://www.whitehouse.gov/the_press_office/TransparencyandOpenGovernment

Piotrowski, S. J., Zhang, Y., Lin, W., \& Yu, W. (2009). Key issues for implementation of Chinese DOG information regulations. Public Administration Review, 69, S129-S135. doi:10.1111/j.1540-6210.2009.02100.x 
Safarov, I., Meijer, A., \& Grimmelikhuijsen, S. (2017). Utilization of open government data: A systematic literature review of types, conditions, effects and users. Information Polity, 22(1), 1-24. doi:10.3233/IP-160012

Saxena, S. (2017). Significance of DOG data in the GCC countries. Digital Policy. Regulation \& Governance, 19(3), 251-263. doi:10.1108/DPRG-02-2017-0005

Saxena, S., \& Muhammad, I. (2018). The impact of DOG data on accountability and transparency. Journal of Economic and Administrative Sciences.

Susha, I., Grönlund, ̊., \& Janssen, M. (2015). Driving factors of service innovation using DOG data: An exploratory study of entrepreneurs in two countries. Information Polity, 20(1), 19-34. doi:10.3233/IP-150353

Van Veenstra, A. F., \& van den Broek, T. A. (2013, September). Opening moves-drivers, enablers and barriers of open data in a semi-public organization. In Proceedings of the International Conference on Electronic Government (pp. 50-61). Springer. doi:10.1007/978-3-642-40358-3_5

Von Lucke, J., \& Große, K. (2014). DOG collaboration. In M. Gascó-Hernández (Ed.), DOG, Public Administration and Information Technology (pp. 189-204). New York: Springer. doi:10.1007/978-1-4614-9563-5_12

Wirtz, B. W., \& Birkmeyer, S. (2015). Open government: Origin, development, and conceptual perspectives. International Journal of Public Administration, 38(5), 381-396. doi:10.1080/01900692.2014.942735

Yang, T. M., Lo, J., \& Shiang, J. (2015). To open or not to open? Determinants of DOG data. Journal of Information Science, 41(5), 596-612. doi:10.1177/0165551515586715

Zuiderwijk, A., \& Janssen, M. (2013, September). A coordination theory perspective to improve the use of open data in policy-making. In Proceedings of the International Conference on Electronic Government (pp. 38-49). Springer. doi:10.1007/978-3-642-40358-3_4

Zuiderwijk, A., \& Janssen, M. (2014a). The negative effects of DOG data-investigating the dark side of open data. In Proceedings of the 15th Annual International Conference on Digital Government Research (pp. 147152). ACM.

Zuiderwijk, A., \& Janssen, M. (2014b). Open data policies, their implementation and impact: A framework for comparison. Government Information Quarterly, 31(1), 17-29. doi:10.1016/j.giq.2013.04.003

Zuiderwijk, A., Janssen, M., \& Dwivedi, Y. K. (2015). Acceptance and use predictors of open data technologies: Drawing upon the unified theory of acceptance and use of technology. Government Information Quarterly, 32(4), 429-440. doi:10.1016/j.giq.2015.09.005 
Muhammad Naeem is doctoral candidate at University of Worcester, (UK). His research interests lies in User Generated Content and Brand Engagement to providing research support to businesses. He holds a twin MBA in Marketing, MBA from University of Sunderland and MBA degree from Virtual University of Pakistan. He has completed his bachelor degree (BSc) in Mathematics and Physics. He is Founder \& Managing Director of successful web marketing agency (snsolutionz.co.uk) since 2013. He is a digital marketing strategist and business coach with 6 years' experience producing social media marketing strategies for SMEs and helping entrepreneurs showcase their talent in the business world. He has produced custom campaigns for several SMEs and directed the personal brand strategies of creative entrepreneurs. He also provides technical Search Engine Optimization (SEO) and copy writing services for business of all sizes. 